\title{
Rectal enhanced CT-scans and acute appendicitis: A modality to exclude appendicitis?
}

\author{
Anders Husted Madsen ${ }^{1}$, Safaa Jaher Al-Ubadi ${ }^{1}$, Dennis Baun Christensen ${ }^{2}$, Joern Baun Christensen ${ }^{2}$ and Mogens Roerbaek Madsen ${ }^{1}$ \\ ${ }^{1}$ Department of Surgery, Herning Regional Hospital, Denmark \\ ${ }^{2}$ Department of Radiology, Herning Regional Hospital, Denmark
}

\begin{abstract}
Background: Acute appendicitis is the common emergency conditions in patients admitted to surgical departments. In most cases the diagnosis is diagnosed easily based on patient history, clinical findings and various laboratory tests. However, in $10-20 \%$ of all operations for appendicitis a normal appendix is found. The aim of this prospective, double-blinded study was to evaluate the validity of rectal contrast-enhanced CT-scan in the diagnosis of acute appendicitis.

Methods: 102 patients with clinically acute appendicitis were CT-scanned prior to the laparoscopic operation. The result of the scan was blinded to the surgeon as well as the operative findings were unknown to the radiologist who evaluated the scans. After the inclusion period, all scans were re-evaluated by an independent, experienced radiologist.

Results: 18 patients had a normal appendix at laparoscopy, 46 patients a mild inflamed appendix and 38 patients a gangrenous or perforated appendix at the time of surgery. The sensitivity was 0.83 and the specificity was 0.94 for the radiologists on call. The expert review of the CT scans had a sensitivity of 0.86 and a specificity of 100 . Approximately $85 \%$ of the patients experienced some degree of discomfort and $67 \%$ of the patients had pain during the scan or the related infusion of rectal administered contrast enema.

Conclusion: CT-scans using rectal contrast enema can reduce the number of negative appendectomies with high sensitivity and specificity rates. However, the widespread use of laparoscopic surgery also in the acute settings in combination with the CT scans needs further evaluation.
\end{abstract}

\section{Background}

Acute appendicitis is one of the most common emergency conditions in patients admitted to surgical departments. In many cases the diagnosis is straight forward based on patient history, clinical findings and various laboratory test [1]. However, in some cases the diagnosis is not obvious and it is generally accepted that 10 to $20 \%$ of patients undergoing surgery for appendicitis have a normal appendix. On the other hand, having an expecting attitude before deciding to operate patients suspected for appendicitis will lead to an increased proportion of patients with perforated or gangrenous appendices. Of these some will develop postoperative complications like wound infection or intraabdominal infections of varying severity [2].

Different studies have aimed at developing algorithms to improve diagnostic accuracy in patients suspected for acute appendicitis. Even though based on large materials, these scoring systems have so far all been without sufficiently predictive accuracy to determine which patients should be operated and which patients should not. During the last 10 to 15 years several studies have been performed comparing imaging modalities like ultrasonography, scintiography and different kinds of CT-scans and particularly contrast-enhanced CT-scans have been promising [3-6].

In a prospective, randomized controlled study, patients were randomised to either 1) CT-scan without contrast or 2) enhanced CT-scan using oral and intravenous contrast or 3) rectal administered contrast. In the latter, appendicitis could be predicted with a high accuracy without having the potential allergic side effects of intravenous administered contrast. Some studies have found that CT-scans delay an operation for appendicitis unnecessarily. These studies recommend that CT-scannings should not be used routinely, but only in selected cases like elderly patients with severe comorbidity, patients with vague symptom or fertile women with unusual symptoms $[7,8]$.

If CT-scans should be used routinely in the diagnostic process of patients suspected of appendicitis, this modality should be available day and night and access to the radiological departments should be without significant delay. Furthermore, the interpretation of a given CT-scan by the radiologist on duty must have sufficiently high predictive value for the surgeon to avoid unnecessary operations and only operate if the diagnosis is clear.

\section{Aim}

The aims of the present study was

- To evaluate the validity of rectal contrast-enhanced CT-scan in the diagnosis of acute appendicitis

- Compare the interpretation of the scans made by the radiologist

Correspondence to: Anders Husted Madsen, Herning Regional Hospital, Gl. Landevej 61, 7400 Herning, Denmark, Tel: 0045-23-28-92-11; Fax: 0045-78-4353-09; E-mail: andemads@rm.dk

Key words: CT-Scans, acute appendicitis, surgery

Received: November 28, 2016; Accepted: December 19, 2016; Published: December 21, 2016 
on duty with the interpretation by a consultant CT-radiologist

- To evaluate the feasibility in an every-day setting of rectal contrast-enhanced CT-scan as a routine examination in patients suspected of acute appendicitis

- To evaluate patient experience of rectal contrast-enhanced CTscan in respect to pain, discomfort, information etc.

\section{Materials and methods}

All patients during a period of 24 months scheduled for emergency operation on suspicion of having acute appendicitis and fulfilling the inclusion criteria (Table 1) were candidates for inclusion in the study. The inclusion period began February 2009. An overview of patients aged 18 or above scheduled for appendicitis during the 24 month period is shown in table 2. At our department no uniform guidelines or algorithms are used to diagnose appendicitis, and the diagnosis was made on clinical grounds by a combination of patient history, typical clinical findings, blood test and urinary tests.

Patients were included prospectively, but not consecutively, as for logistic reasons like certain holidays and on days with extraordinary workload in the department of radiology. The patient population is seen in table 3 .

After inclusion, the patients underwent a rectal-enhanced CT scan using a Phillips Brilliance CT-scanner. A rectal catheter was introduced 20 minutes before the CT scan and one liter of isotonic Saline mixed with $40 \mathrm{ml} .270 \mathrm{mg} / \mathrm{ml}$ Visipaque purged into the patient's rectum and colon while the patient was lying on the left side. Ten minutes before the scan, the patient was asked to lie on the right side. Initially, a frontal and side surview of the abdomen was taken. The CT-scan was performed as a 64 slice scan from the top of the third lumbar vertebrae to

Table 1. Inclusion / exclusion criteria.

\section{Inclusion:}

Clinical suspicion of acute appendicitis and scheduled for emergency operation

Exclusion:

Age $<18$ years

Pregnancy

Unable to cooperate during the CT-scan

Unable to read and understand Danish

Table 2. Patient population.

\begin{tabular}{|l|c|}
\hline Patients scheduled for appendicectomy & 370 \\
\hline Not included* & 152 \\
\hline Declined partipation & 58 \\
\hline Excluded according to exclusion criterias & 23 \\
\hline $\begin{array}{l}\text { Included, but CT scans not performed because of } \\
\text { prolonged waiting time }\end{array}$ & 35 \\
\hline Total number of patients included and scanned & 102 \\
\hline
\end{tabular}

Total number of patients included and scanned

102

*patients were not included because of holidays, surgeons who forgot to include the patients etc.

Table 3. Basic data of included patients.

\begin{tabular}{|l|c|c|}
\hline Number of patient included & $\mathrm{N}=102$ & \\
\hline Age & $44.22(\mathrm{mean})$ & $18-86(\mathrm{~min}-\max )$ \\
\hline Gender & Women: $\mathrm{N}=47$ & Men: $\mathrm{N}=55$ \\
\hline Duration of symptoms & More than 12 hours: 98 & Less than 12 hours: 4 \\
\hline Temperature & $37.6^{\circ} \mathrm{C}$ & $35.7-39.8(\min -\max )$ \\
\hline Pulse & $82($ Heart rate per minute) & $36-117(\min -\max )$ \\
\hline Hemoglobinlevel & $8.8 \mathrm{mmol} / \mathrm{L}$ & $6.9-10.9(\min -\max )$ \\
\hline Leucocyte count & 13.0 & $(2.0-27.9)$ \\
\hline C reactive protein level & $70 \mathrm{mmol} / \mathrm{L}$ & $(0.2-445)$ \\
\hline S-creatinine & $71 \mu \mathrm{mol} / \mathrm{L}$ & $(37-104)$ \\
\hline
\end{tabular}

the top of the acetabulum. The X-raying dose was approximately three milliSievert, which is less than a traditional X-ray of the colon a.m. Welin. When the rectal-enhanced CT scan was performed, the radiologist on duty evaluated the result of the scan, noted the findings of the scan in a questionnaire, and sent the questionnaire to the project office. The surgeon did therefore not know the result of the scan prior to the operation and the radiologist did not known the findings at the operation, during which the appendix was removed laparoscopically if inflamed. The department of pathology examined all removed appendices.

When the patients were discharged or within one week after discharge the patients were contacted by a project nurse for a follow-up interview about the patients experience with the CT scan.

When the study period was over, all scans were re-evaluated by an experienced CT-radiologist, who was blinded in respect to the initial evaluation of the scans as well as the operative findings.

All patients received both written and oral information about the study and gave informed consent before entering the study. The study was approved by The Regional Committee on Health Research Ethics and the Danish Data Protection Agency.

\section{Results}

A total of 102 patients were included in the study. Fifty-five patients were males (54\%) and mean age was 44.2 years (18-86 years). The average waiting time for the CT-scans were 2.12 hours ( $\min 0.98-\max$ 25.8) and the average waiting time for operations were 5.50 hours ( $\mathrm{min}$ 1.5 - 31.5 hours)

As shown in table 4, 18 patients had a normal appendix at laparoscopy, 46 patients a mild inflamed appendix and 38 patients a gangrenous or perforated appendix at the time of surgery. In thirteen cases the radiologist on call could not determine if the appendix was inflamed or not. By the second review of the scans this was only in four cases. The sensitivity was $0.83(60 /(60+12))$ and $0.86(70 /(70+11))$ for the radiologist on call and the expert review of the CT scans, respectively. The specificities calculated was $0.94(16 / 17)$ and 100 (17/17).

Table 5 shows the evaluation by the patients of the CT-scans. Approximately $85 \%$ of the patients experienced some degree of discomfort and $67 \%$ of the patients had pain during the scan or the related infusion of rectal administered contrast enema. However, 92 of the 102 patients were willing to have the scan performed again while seven patients were not.

\section{Discussion}

Numerous studies evaluating different imaging modalities in diagnosing acute appendicitis have been made. Many of these studies are retrospective studies. In our study we have evaluated rectal adminis-

Table 4. Appendicitis suspected on CT scan, evaluation by radiologist and specialist.

\begin{tabular}{|l|l|c|c|c|}
\hline \multicolumn{2}{|l|}{} & Inflamed & Normal appendix & Total \\
\hline $\begin{array}{l}\text { Appendicitis suspected } \\
\text { on CT scan, evaluation } \\
\text { by radiologist on duty }\end{array}$ & Yes & 60 & 1 & 61 \\
\cline { 2 - 5 } & No & 12 & 16 & 28 \\
\cline { 2 - 5 } & Undeterminable & 12 & 1 & 13 \\
\cline { 2 - 5 } & Total & 84 & 18 & 102 \\
\cline { 2 - 5 } & & 70 & 0 & 70 \\
\hline $\begin{array}{l}\text { Appendicitis suspected } \\
\text { on CT scan, evaluation } \\
\text { by specialist }\end{array}$ & Yes & 11 & 17 & 28 \\
\cline { 2 - 5 } & No & 3 & 1 & 102 \\
\hline
\end{tabular}


trated contrast enema using a low radiation dose in a prospective study. Our results show that this method in case of normal findings at CT scans does not overlook many patients with appendicitis. Actually we found a specificity of $94 \%$ when the CT scans were evaluated by the radiologists on call and $100 \%$ when the CT scans were evaluated by a CT specialist. However, it can be argued that the number of patients is low making these and the confidence intervals would therefore be wide.

In this study, we included only patients that clinically had appendicitis and the surgeons would therefore make an operation. If the radiologist was in doubt of the result of the scan, they might have said that appendicitis is likely to be present, because they knew that the patients were about to undergo an operation for appendicitis. In all cases where the radiologist was unable to determine if the appendix was inflamed, appendicitis was found at the operation making this potential bias of probably little significance as shown in table 4 .

Only patients in which the surgeon decided to make an operation was included in the study. If taken into account the large number of patients that for different reasons was not included, it can be argued that only the clear cases were included. This could be a potential bias of the result. However, the main explanation for the prolonged inclusion period is rather that the surgeons forgot to include the patients.

In our study, we found a very high specificity of $94 \%$ and a sensitivity of $86 \%$ using only rectal contrast. The interpretations of CTscans by younger radiologist on call compared to more experienced radiologist have been evaluated in a single study [9]. In this study, only minor differences were found and these differences did not alter the treatment of the patients. Indeed, we found a similar result as shown in table 4. Other studies have found similar results $[7,10]$.

All patients in our study were interviewed after the CT scans. As seen in table 5 most patients experienced some kind of discomfort. We believe that it is of importance to have information about patient discomfort when introducing a new investigation modality. If the proportion of patients with discomfort of any degree is unacceptably high, is a subject for discussion and must be weighed up against the benefit of the method. In our study we did not take the consequence of a normal scan but operated the patients as planned. On the other hand, using other contrast enhancing modalities like intravenous contrast there is the risk of severe side effects like allergic reactions and nephrotoxicity $[7,8]$.

Latifi et al. [10] examined in a retrospective study if additional oral or intravenous contrast increased the accuracy. Even though some of the groups were rather small, they did not find an increase in accuracy using more than one contrast modality. Mun et al. [11] found high sensitivities and specificities using intravenous contrast in their retrospective study. In a Dutch study was found a high sensitivity and specificity using unenhanced CT scans [12]. An interesting study by Shaligram et al. [13] showed that patients undergoing CT imaging compared with those without a CT scan had less morbidity and fewer 30-day readmissions. However, CT imaging resulted in a higher overall length of hospital stay and a higher total cost.

Table 5. The table shows the patients perception of pain and discomfort of the CT scans.

\begin{tabular}{|c|c|c|}
\hline & Discomfort & pain \\
\hline None & $16(15.7 \%)$ & $37(36.3 \%)$ \\
\hline Easy & $34(33.3 \%)$ & $29(28.4 \%)$ \\
\hline Moderate & $27(26.5 \%)$ & $13(12.7 \%)$ \\
\hline Hard & $25(24.5 \%)$ & $23(22.5 \%)$ \\
\hline Total & $102(100 \%)$ & $102(100 \%)$ \\
\hline
\end{tabular}

Based upon our results and other similar studies it seems that CT scans using rectal contrast enema can reduce the number of negative appendectomies with high sensitivity and specificity rates. However, which contrast modality (intravenous, oral or rectal) is superior to the others is unclear. Further, the widespread use of laparoscopic surgery also in the acute settings in combination with the CT scans also needs further evaluation as well as the economic costs. We therefore recommend that the use of CT scans in the diagnosis of acute appendicitis must be evaluated in a large randomized trial.

\section{Compliance with ethical standards}

This study was not funded by any grants.

All participating patients gave written informed consent. The study is in accordance and approved by the local scientific ethical committee and with the 1964 Helsinki declaration and its later amendments or comparable ethical standards.

\section{Conflicts of interest}

None of the authors have any financial or any other conflicts of interest to declare.

\section{References}

1. Paulson EK, Kalady MF, Pappas TN (2003) Clinical practice. Suspected appendicitis. $N$ Engl J Med 348: 236-242. [Crossref]

2. Hardin DM Jr (1999) Acute appendicitis: review and update. Am Fam Physician 60 2027-2034. [Crossref]

3. Alobaidi M, Shirkhoda A (2003) Value of bone window settings on CT for revealing appendicoliths in patients with appendicitis. AJR Am J Roentgenol 180: 201-205. [Crossref]

4. Ames Castro M, Shipp TD, Castro EE, Ouzounian J, Rao P (2001) The use of helical computed tomography in pregnancy for the diagnosis of acute appendicitis. $\mathrm{Am} \mathrm{J}$ Obstet Gynecol 184: 954-957. [Crossref]

5. Augustin T, Bhende S, Chavda K, VanderMeer T, Cagir B (2009) CT scans and acute appendicitis: a five-year analysis from a rural teaching hospital. J Gastrointest Surg 13: 1306-1312. [Crossref]

6. Curtin KR, Fitzgerald SW, Nemcek AA Jr, Hoff FL, Vogelzang RL (1995) CT diagnosis of acute appendicitis: imaging findings. AJR Am J Roentgenol 164: 905-909. [Crossref]

7. Hershko DD, Awad N, Fischer D, Mahajna A, Guralnik L, et al. (2007) Focused helical CT using rectal contrast material only as the preferred technique for the diagnosis of suspected acute appendicitis: a prospective, randomized, controlled study comparing three different techniques. Dis Colon Rectum 50: 1223-1229.

8. Hershko DD, Sroka G, Bahouth H, Ghersin E, Mahajna A, et al. (2002) The role of selective computed tomography in the diagnosis and management of suspected acute appendicitis. Am Surg 68: 1003-1007. [Crossref]

9. Ruchman RB, Jaeger J, Wiggins EF 3rd, Seinfeld S, Thakral V, et al. (2007) Preliminary radiology resident interpretations versus final attending radiologist interpretations and the impact on patient care in a community hospital. AJR Am J Roentgenol 189: 523526. [Crossref]

10. Latifi A, Labruto F, Kaiser S, Ullberg U, Sundin A, et al. (2011) Does enteral contrast increase the accuracy of appendicitis diagnosis? Radiol Technol 82: 294-299. [Crossref]

11. Mun S, Ernst RD, Chen K, Oto A, Shah S, et al. (2006) Rapid CT diagnosis of acute appendicitis with IV contrast material. Emerg Radiol 12: 99-102. [Crossref]

12. in't Hof KH, van Lankeren W, Krestin GP, Bonjer HJ, Lange JF, et al. (2004) Surgical validation of unenhanced helical computed tomography in acute appendicitis. Br J Surg 91: 1641-1645. [Crossref]

13. Shaligram A, Pallati P, Simorov A, Meyer A, Oleynikov D (2012) Do you need a computed tomographic scan to evaluate suspected appendicitis in young men: an administrative database review. Am J Surg 204: 1025-1030. [Crossref]

Copyright: (C2016 Madsen AH. This is an open-access article distributed under the terms of the Creative Commons Attribution License, which permits unrestricted use, distribution, and reproduction in any medium, provided the original author and source are credited. 